Check for updates

Cite this: Mater. Adv., 2020 1,3428

Received 23rd September 2020, Accepted 2nd November 2020

DOI: 10.1039/d0ma00728e

rsc.li/materials-advances

\section{Versatile nature of anthanthrone based polymers as active multifunctional semiconductors for various organic electronic devices $\dagger$}

\author{
Qian Liu, (D) ${ }^{a}$ Yang Wang, (D) ${ }^{b}$ Lingeswaran Arunagiri, ${ }^{c}$ Muhammad Khatib, ${ }^{d}$ \\ Sergei Manzhos, (iD ${ }^{e}$ Krishna Feron, ${ }^{\mathrm{fg}}$ Steven E. Bottle, ${ }^{\text {ah }}$ Hossam Haick, (iD ${ }^{\mathrm{d}}$ \\ He Yan, (D) ${ }^{c}$ Tsuyoshi Michinobu (D) $^{b}$ and Prashant Sonar (D) *ah
}

\begin{abstract}
The versatility of anthanthrone-based materials in organic electronics is exploited by synthesizing four polymers, PANT, PANT-TBO, PANT-TBT, and PANT-TffBT. PANT represents the self-coupled homopolymer, while the other three are D-A (donor-acceptor) type copolymers. Each of them is successfully applied in three different devices, namely organic field-effect transistors (OFETs), organic photovoltaic cells (OPVs), and chemical sensors. The results indicate that anthanthrone could be a very promising building block for the construction of semiconductors for multi-purpose applications. Specifically, the four polymers exhibit $p$-type properties in OFETs with hole mobility values in the range of $10^{-4}-10^{-3} \mathrm{~cm}^{2} \mathrm{~V}^{-1} \mathrm{~s}^{-1}$. In OPVs, the power conversion efficiencies (PCEs) of non-fullerene cells have a wide range from $0.28 \%$ to $5.21 \%$. This indicates that the efficiency may reach a higher value via further structural modification by selecting suitable comonomers to produce new polymers. Additionally, based on the parameters of the OFET sensor devices and the variation in the backbone structures of the four polymers, they show varying response trends for four chemicals: octane, toluene, isopropanol and acetic acid, indicating the important role of the structural composition in generating different chemical sensitivities and fingerprints for sensing. Overall, we clearly disclose the potential of four new anthanthrone-based polymers in various types of electronic devices.
\end{abstract}

\section{Introduction}

In recent decades, organic electronics have attracted tremendous attention due to some recognized advantages compared with their inorganic counterparts, including low production costs,

\footnotetext{
${ }^{a}$ School of Chemistry and Physics, Science and Engineering Faculty, Queensland University of Technology, Brisbane, QLD 4000, Australia.

E-mail: sonar.prashant@qut.edu.au

${ }^{b}$ Department of Materials Science and Engineering, Tokyo Institute of Technology, 2-12-1 Ookayama, Meguro-ku, Tokyo 152-8552, Japan

${ }^{c}$ Department of Chemistry and Hong Kong Branch of Chinese National Engineering Research Centre for Tissue Restoration and Reconstruction, Hong Kong University of Science and Technology, Clear Water Bay, Kowloon, Hong Kong, China

${ }^{d}$ Department of Chemical Engineering and Russell Berrie Nanotechnology Institute Technion - Israel Institute of Technology, Haifa 3200003, Israel

${ }^{e}$ Centre Énergie Matériaux Télécommunications, Institut National de la Recherche Scientifique, 1650 boulevard Lionel-Boulet, Varennes, QC J3X1S2, Canada

${ }^{f}$ CSIRO Energy Centre, 10 Murray Dwyer Circuit, Mayfield West, NSW 2304, Australia

${ }^{g}$ Centre for Organic Electronics, University of Newcastle, Callaghan, NSW 2308, Australia

${ }^{h}$ Centre for Materials Science, Queensland University of Technology, Brisbane, QLD 4000, Australia

$\dagger$ Electronic supplementary information (ESI) available: Experimental details, thermal properties, DFT calculations, OFET device structure, output curves, AFM images, GPC curves, and NMR spectra. See DOI: 10.1039/d0ma00728e
}

light weight, mechanical flexibility and large-area manufacturing using a roll-to-roll method. ${ }^{1}$ The corresponding devices include organic field-effect transistors (OFETs), organic photovoltaic cells (OPVs), perovskite solar cells (PSCs), organic lightemitting diodes (OLEDs), dye-sensitized solar cells (DSSCs), chemical sensors, logic circuits and many more. ${ }^{2-9}$ Despite these advantages, their limited device performance is currently the major barrier to their commercialization. ${ }^{10}$ Therefore, extensive efforts have continuously been made to improve the device performance, particularly for OFETs and solar cells (OPVs and PSCs). ${ }^{11-14}$ Among all these efforts, it is apparent that the development of organic semiconductors (OSCs), which provide the core functionality of the devices, has played a significant role in advancing this field.

The greatest merits of OSCs are their solution processability and tunable optoelectronic properties via rational molecular design. Promising building blocks used to construct OSCs for high-performance electronic devices are generally found to meet the following criteria: (i) containing a conjugated backbone that is the basis of OSCs; ${ }^{15}$ (ii) easy alkylation to make them soluble in common organic solvents; (iii) multiple active reaction points to allow diverse chemical modifications for tuning the optoelectronic properties; and (iv) accessible 
coupling reactions to afford target small molecular or polymeric semiconductors. Some exemplary conjugated building blocks, such as diketopyrrolopyrrole (DPP), ${ }^{16}$ benzodithiophene (BDT), ${ }^{17}$ isoindigos (II), ${ }^{18,19}$ and naphthalene diimide (NDI), ${ }^{20}$ have shown great potential in such devices. All these moieties are not only available through 1-step or few-step highyielding syntheses, they can also be easily alkylated, making them soluble in commonly used organic solvents. In addition, the easy introduction of different aromatic groups to the backbone or side chain can finely tune the optoelectronic properties of the resultant OSCs, thus adjusting the performance of the corresponding devices. For example, the DPP moiety consists of two 5-membered ring unsaturated cyclic amides (lactams) fused together to give a highly conjugated structure with an excellent electron affinity, which makes it suitable for both OFETs and OPVs. ${ }^{21}$ The incorporation of flanking groups at the 3,6-positions of the DPP unit results in varied conjugation lengths and a highest occupied molecular orbital (HOMO) distribution along the conjugated backbone, which enables rational molecular design to suit specific electronic device applications. The BDT moiety is even more appropriate to make either $1 \mathrm{D}$ or $2 \mathrm{D}$ semiconductors by structural modifications along the directions of the 2,6- or 4,8-positions or both. ${ }^{22}$ This class of compounds has greatly boosted the field of organic electronics and some resultant OSCs have demonstrated among the best performances in the corresponding devices. $^{23,24}$ However, it was found that there are few OSCs that can simultaneously work well in various types of electronic devices except some specially designed materials for both OPVs and OFETs. ${ }^{21}$

4,10-Dibromoanthanthrone (ANT, Fig. 1), also called VAT Orange 3 , is a commercially available organic dye with a very low cost; this dye has several interesting features and can be used as a building block in organic electronics. ${ }^{25}$ First, the four reactive sites (bromine atoms on the 4,10-positions or carbonyl groups on the 6,12-positions) allow easy structural modification along two axes to fine tune the optoelectronic properties of the resultant OSCs. ${ }^{26}$ Second, as a member of the polycyclic aromatic hydrocarbons, the fused-ring structure with high $\pi$ conjugation enables it to stack in well-organized arrays in the solid state, which is significantly beneficial for certain devices, such as OFETs and OPVs. ${ }^{27}$ As shown in Scheme S1 in the ESI, $\dagger$ to the best of our knowledge, we have outlined all the ANTbased materials used in electronic devices. It can be clearly seen that ANT derivatives have been separately used in several types of devices in the field of organic electronics (OFETs, OPVs, DSSCs, PSCs, and OLEDs); however, the device performance still needs to be improved. Other than the applications in organic electronics, large numbers of ANT compounds have been synthesized to disclose the intrinsic properties of ANT. ${ }^{26-37}$ As mentioned above, to date, there are few materials that can be simultaneously used in various types of electronic devices. ANTbased materials have shown potential in different devices separately; thus, we are interested to demonstrate that ANTbased materials can simultaneously function well in several different devices, highlighting their multi-purpose applications.
In this study, four ANT-based polymers have been successfully designed and synthesized via organometallic coupling reaction. PANT is a homo-coupled polymer, while the other three, PANT-TBO, PANT-TBT and PANT-TffBT, are D-A (donoracceptor) type copolymers. Their energy levels, and thermal, optical and electronic properties are comprehensively studied. Each of the four polymers is used as an active semiconductor in OFETs, OPVs, and chemical sensors. These polymers simultaneously function well in the three different devices, clearly highlighting their versatility in different applications. Although the initial performance characteristics are not as high as those of some previously reported materials, there is great scope to enhance performance via device optimization and engineering. Overall, in this work, we report the multi-purpose applications of four newly developed ANT-based polymers in three different types of devices.

\section{Results and discussion}

To the best of our knowledge, only two ANT-based polymers, PTTC and PTVTC shown in Scheme S1 (ESI $\dagger$ ), have been reported for use in OFETs and OPVs. To further study the performance of ANT-based polymers in electronic devices, we designed and synthesized four new polymers, PANT, PANT-TBO, PANT-TBT and PANT-TffBT, using Suzuki coupling (Scheme 1 and Fig. 1). PANT is a homo-coupled polymer, while the other three represent the well-known D-A type materials. Regarding the synthesis, as shown in Scheme 1, the 6,12positions of ANT are easily alkylated by 2-decyltetradecyl bromide in the presence of a base $\left(\mathrm{Na}_{2} \mathrm{~S}_{2} \mathrm{O}_{4}\right)$ and a phase transfer catalyst (aliquat 336) in aqueous $\mathrm{NaOH}$. The boronic ester of alkylated ANT is obtained by following a commonly used procedure, ${ }^{38}$ while the three dibromo acceptors are commercially available. The target polymers, PANT, PANT-TBO, PANT-TBT and PANT-TffBT, were successfully synthesized via Suzuki coupling polymerization. The detailed synthetic procedures are shown in the Experimental section and the chemical structures of the synthesized compounds were characterized using nuclear magnetic resonance (NMR) spectra, which are available in the ESI. $\dagger$

The thermal properties of the four polymers were evaluated using thermogravimetric analysis (TGA) and differential scanning calorimetry (DSC). From the TGA thermograms shown in Fig. S1 (ESI $\dagger$ ), it can be observed that all the polymers exhibit good thermal stability with a decomposition temperature ( $T_{\mathrm{d}}, 5 \%$ weight loss) higher than $250{ }^{\circ} \mathrm{C}$. The $T_{\mathrm{d}}$ values of these newly developed polymers enable device performance optimization using thermal annealing treatment. From the DSC measurements (Fig. S2a-d, ESI $\dagger$ ), it can be observed that only PANT exhibits a weak melting/crystalline peak at $182{ }^{\circ} \mathrm{C}$ and $148{ }^{\circ} \mathrm{C}$, respectively, demonstrating its slightly better crystallinity than that of the D-A type polymers for which no obvious transitions were observed during the heating and cooling processes between $25{ }^{\circ} \mathrm{C}$ and $220{ }^{\circ} \mathrm{C}$. However, overall, the crystallinity of all four polymers is low, as reflected in the 

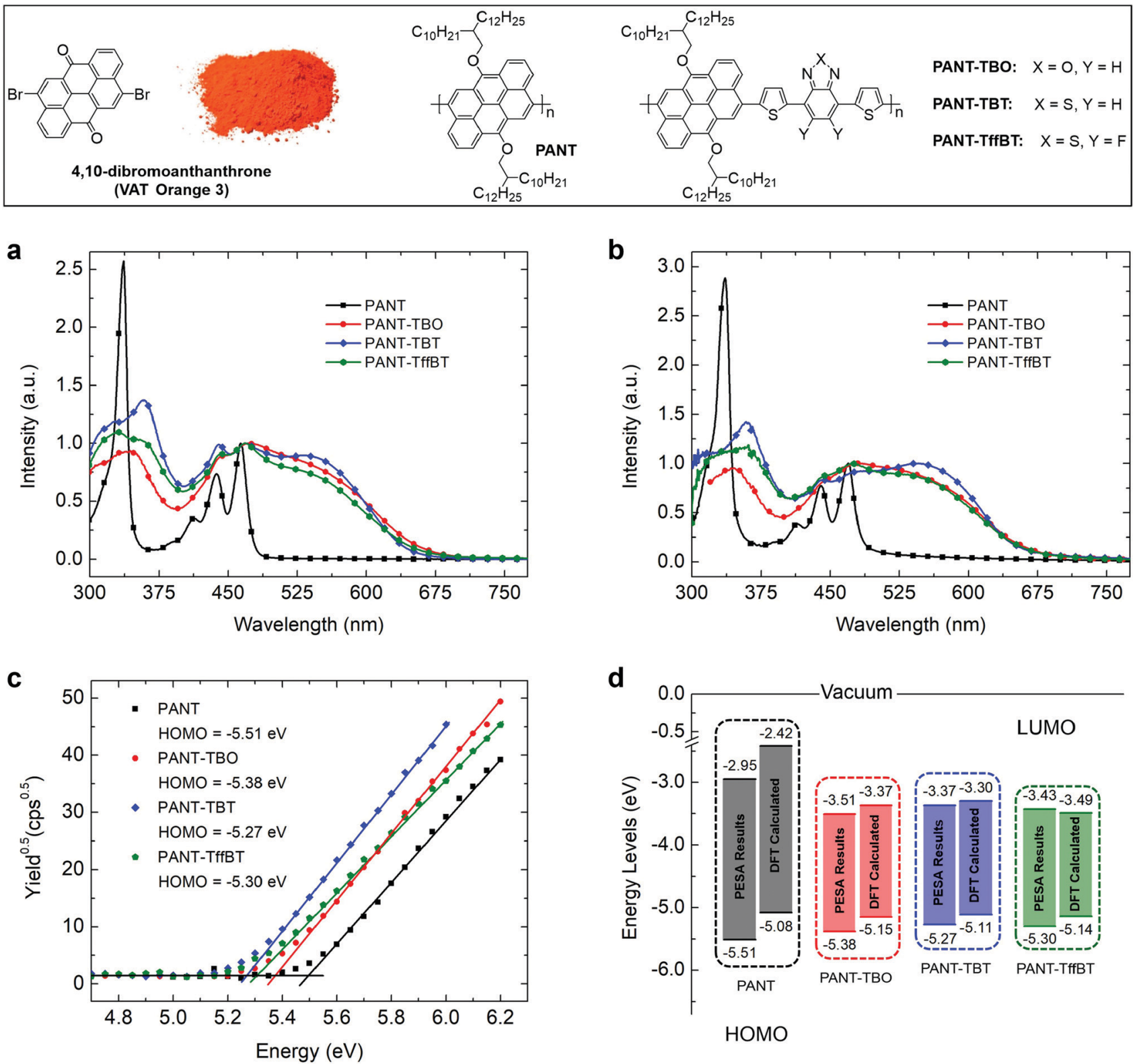

Fig. 1 The chemical structures of 4,10-dibromoanthanthrone (and its appearance in solid state powder form) and the four polymers; the UV-Vis absorption spectra of the polymers (a) in chloroform solutions and (b) as thin films; (c) their HOMO energy levels determined through PESA measurements; (d) the energy level diagram with both PESA and DFT calculated results.

thin film XRD patterns (Fig. S2e, ESI $\dagger$ ) where no obvious crystalline peaks were observed. This could be one of the reasons why the overall device performance is low in the thin film related OFETs (vide infra).

A comparison of the UV-Vis absorption spectra of the four polymers in dilute chloroform solution or thin film form is shown in Fig. 1a and b and the corresponding optical data are summarized in Table 1. It can be observed that, in both solutions and thin films, the absorption spectra appear as two absorption bands that have been reported for most conjugated materials and are ascribed to the $\pi-\pi^{*}$ transition of the conjugated backbone for the high energy band within $300-400 \mathrm{~nm}$ and the intramolecular charge transfer (ICT) effect for the low energy band within $400-700 \mathrm{~nm}$. For PANT, the ICT peak is lower (i.e. a low absorption coefficient) than the $\pi-\pi^{*}$ transition peak, while after introducing acceptors, the ICT peaks of PANT-TBO, PANT-TBT and PANT-TffBT are greatly enhanced due to the more efficient ICT between the donor (ANT) and the incorporated acceptor units in the backbone. In solutions, some well-defined peaks are observed, indicating multiple intermolecular interactions. However, in thin films, the peaks of PANT-TBO, PANT-TBT and PANT-TffBT become broadened, resulting in a single dominant peak located at 480 , 547 and $474 \mathrm{~nm}$, respectively, indicating that the aggregation becomes more ordered and $\pi$ stacking emerges in the solid state. For PANT, both the solution and thin film spectral shapes 


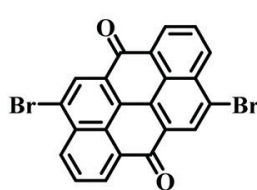

ANT

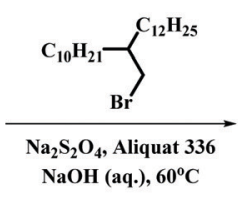

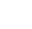

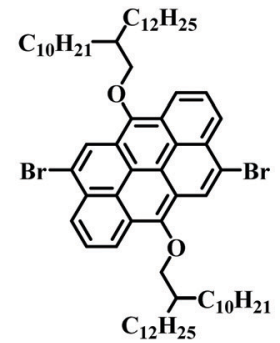

C24-ANT

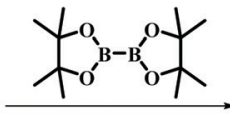

KOAc, Pd(dppf) $\mathrm{Cl}_{2}$ Anhydrous 1,4-dioxane $110^{\circ} \mathrm{C}$

$110^{\circ} \mathrm{C}$

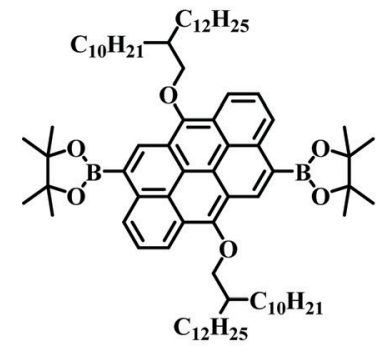

BE-C24-ANT

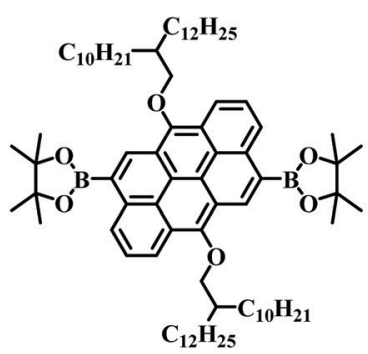

BE-C24-ANT
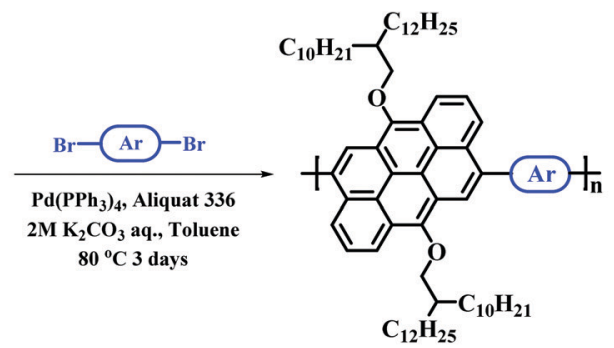

Polymers

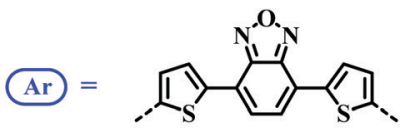

PANT-TBO

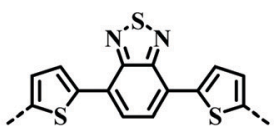

PANT-TBT

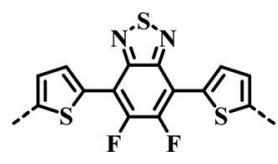

PANT-TffBT

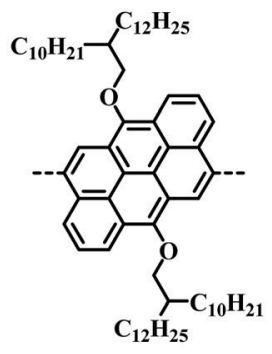

PANT

Scheme 1 The synthetic routes to the four new polymers based on the low-cost anthanthrone dye molecule using Suzuki coupling polymerization.

are almost the same, with only a small red shift in the thin film spectrum, indicating weak $\pi$ aggregation. This is probably due to the large dihedral angle between two ANT groups, which was determined to be $74^{\circ}$ using DFT calculations (vide infra). PANT-TBT shows a larger red shift from solution to thin film compared with those of the other three, indicating a more effective backbone stacking. The absorption edge wavelengths of the thin films were determined to be $484 \mathrm{~nm}$ for PANT, $664 \mathrm{~nm}$ for PANT-TBO, $653 \mathrm{~nm}$ for PANT-TBT and $663 \mathrm{~nm}$ for PANT-TffBT, which correspond to the optical bandgaps of $2.56,1.87,1.90$ and $1.87 \mathrm{eV}$, respectively. The larger bandgap of PANT is ascribed to the absence of acceptor groups along the backbone.

The energy levels, including the highest occupied molecular orbital (HOMO) and lowest unoccupied molecular orbital (LUMO), are some of the most important parameters for semiconductors because the operating principle of electronic devices, especially for transistors and solar cells, is often explained according to the energy level differences between materials used in the corresponding devices. ${ }^{39}$ To determine the energy levels of all four polymers, we performed measurements of photoelectron spectroscopy in air (PESA). As shown in Fig. 1c, the HOMO energy levels are found to be $-5.51 \mathrm{eV}$ for PANT, $-5.38 \mathrm{eV}$ for PANT-TBO, $-5.27 \mathrm{eV}$ for PANT-TBT and $-5.30 \mathrm{eV}$ for PANTTffBT. By incorporating the optical bandgaps, the LUMO energy levels are estimated to be $-2.95,-3.51,-3.37$ and $-3.43 \mathrm{eV}$, respectively.

To gain insight into the electronic structure of the four polymers, density functional theory (DFT) calculations were performed on dimer models with abridged alkyl chains. As shown in Fig. 2, the electron density of both the HOMO and LUMO is fully delocalized over the entire molecule for the PANT

Table 1 Summary of optical properties and energy levels

\begin{tabular}{|c|c|c|c|c|c|c|}
\hline Materials & $\lambda_{\max }^{\mathrm{sol}} / \mathrm{nm}$ & $\lambda_{\max }^{\mathrm{film}} / \mathrm{nm}$ & $\lambda_{\text {onset }}^{\text {filmm }} / \mathrm{nm}$ & $E_{\mathrm{g}}^{\mathrm{opt}} / \mathrm{eV}$ & $\mathrm{HOMO} / \mathrm{eV}$ & LUMO/eV \\
\hline PANT-TBO & 472,343 & 480,347 & 664 & $1.87^{a}$ & $-5.38^{b} ;-5.15^{d}$ & $-3.51^{c} ;-3.37^{d}$ \\
\hline
\end{tabular}

${ }^{a} E_{\mathrm{g}}^{\mathrm{opt}}=1240 / \lambda_{\text {onset }}{ }^{\text {film }}{ }^{b}$ PESA results. ${ }^{c}$ LUMO $=\mathrm{HOMO}^{\mathrm{b}}+E_{\mathrm{g}}^{\mathrm{opt}} \cdot{ }^{d}$ DFT calculated results. 


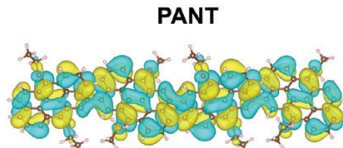

$\mathrm{HOMO}=-5.08 \mathrm{eV}$

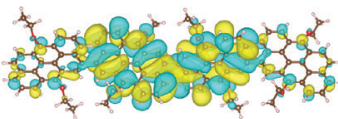

$\mathrm{UMO}=-2.42 \mathrm{eV}$

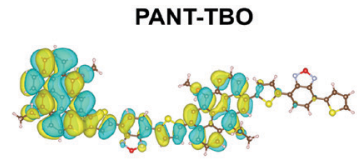

$\mathrm{HOMO}=-5.15 \mathrm{eV}$

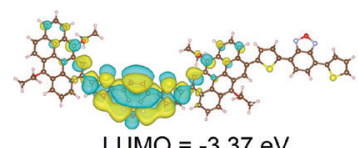

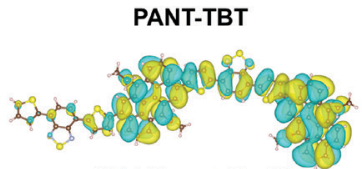

$\mathrm{HOMO}=-5.11 \mathrm{eV}$

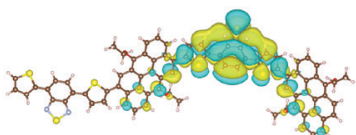

LUMO $=-3.30 \mathrm{eV}$
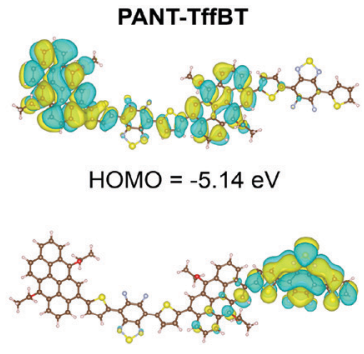

LUMO $=-3.49 \mathrm{eV}$

Fig. 2 DFT calculated molecular frontier orbital distributions (HOMO and LUMO) for the polymer dimer models; the alkyl chains on ANT were replaced with ethyl groups.

polymer. However, for the other three $\mathrm{D}-\mathrm{A}$ polymers, the HOMO is mainly distributed over the $\pi$-conjugated ANT donor core and the LUMO is delocalized at the acceptor segment. The optimized geometry structures of the model dimers (front and side views shown in Fig. S3 in the ESI $\dagger$ ) suggest that PANT has a dihedral angle of $74^{\circ}$ between the adjacent two ANT groups, while the three D-A polymers have the same dihedral angles of $45^{\circ}$ between the ANT and acceptor segments. The large dihedral angle of PANT indicates a large steric hindrance among the ANT groups. For the three D-A polymers, the introduction of acceptors greatly decreases the steric hindrance because the acceptors, on the one hand, have no extra side chains and, on the other hand, involve two thiophene $\pi$-bridges, both of which are beneficial for decreasing the dihedral angle. The calculated HOMO and LUMO energy levels are summarized in both Fig. 1d and Table 1. Optical absorption spectra were computed using time-dependent DFT, as shown in Fig. S4 (ESI $\dagger$ ). They confirm the significant red shift of the spectra of the copolymers $v s$. the PANT homopolymer observed experimentally as well as a much higher absorption intensity of the copolymers. The computed absorption spectra are redshifted due to the charge-transfer nature of the transitions.

\section{Organic field-effect transistor performance}

The charge transport properties of these four polymers were investigated by fabricating organic field-effect transistors using the top-contact/bottom-gate (TC/BG) device configuration (Fig. S5, ESI $\dagger$ ). The organic semiconducting thin films were formed in an argon-filled glovebox by spin-casting the polymer solutions $\left(4 \mathrm{mg} \mathrm{mL} \mathrm{mL}^{-1}\right.$ in chloroform) on $\mathrm{SiO}_{2}(300 \mathrm{~nm}) / \mathrm{n}^{++}-\mathrm{Si}$ substrates that were first modified with a self-assembled monolayer (SAM) of octadecyltrimethoxysilane (OTMS). Thermal annealing treatments were conducted in the same glovebox using the selected temperatures of 200,250 or $270{ }^{\circ} \mathrm{C}$. After this, $\sim 50 \mathrm{~nm}$ of thick gold was deposited as the source and drain contacts using a shadow mask. The detailed fabrication procedure is described in the ESI. $\dagger$ Typical $I-V$ curves and parameters of the transistors are shown in Fig. 3a-d, Fig. S6a-d (ESI $\dagger$ ), Table 2 and Tables S1-S4 (ESI $\dagger$ ). All four polymers exhibit unipolar p-type charge transport properties under laboratory ambient conditions with the hole mobility in the range of $10^{-4}$ to $10^{-3} \mathrm{~cm}^{2} \mathrm{~V}^{-1} \mathrm{~s}^{-1}$. Specifically, the homopolymer PANT-based transistors display a peak mobility of $2.2 \times 10^{-3} \mathrm{~cm}^{2} \mathrm{~V}^{-1} \mathrm{~s}^{-1}$ at the optimized thermal annealing temperature of $200{ }^{\circ} \mathrm{C}$ (Fig. 3a and Table 2). In comparison with the reported PTTC and PTVTC polymers (with similar electronrich groups along the backbone) ${ }^{40}$ the backbone of the PANT polymer resulted in improved crystallinity, as observed from the DSC curve and AFM image (vide infra) data, and this is a key parameter that enhances the hole mobility. Further work on the improvement of backbone coplanarity and crystallinity may significantly enhance the mobility in OFETs, and we have been evaluating design principles via modelling studies. After introducing the acceptor unit TBO into the polymer backbone to form a donor-acceptor type material for better intermolecular charge transport, the copolymer PANT-TBO-based devices showed a lower hole mobility of $2.9 \times 10^{-4} \mathrm{~cm}^{2} \mathrm{~V}^{-1} \mathrm{~s}^{-1}$ (Fig. $3 \mathrm{~b}$ and Table 2). Promisingly, by changing TBO to the TBT unit, the hole mobility was dramatically enhanced to $4.5 \times$ $10^{-3} \mathrm{~cm}^{2} \mathrm{~V}^{-1} \mathrm{~s}^{-1}$ (Fig. 3c and Table 2). The improved performance is partially due to the shallowest HOMO energy level among the four polymers, which could favour easier hole injection from the Au electrodes. Unfortunately, the fluorinated polymer PANT-TffBT exhibits a lower hole mobility, around $10^{-4} \mathrm{~cm}^{2} \mathrm{~V}^{-1} \mathrm{~s}^{-1}$. Even after various thermal annealing optimization treatments, its peak mobility only reached $5.0 \times$ $10^{-4} \mathrm{~cm}^{2} \mathrm{~V}^{-1} \mathrm{~s}^{-1}$ (Fig. 3d, Table 2 and Table S4, ESI $\dagger$ ). We attribute its poor transistor performance to its low molecular weight and large polydispersity index. The GPC curve of PANTTffBT (Fig. S7, ESI $\dagger$ ) shows two peaks, indicating a relatively large number of low-molecular-weight fractions. As a result, a large polydispersity index of 3.25 was obtained. The surface morphology of the four polymer films was studied using atomic force microscopy (AFM) (Fig. 3e-l and Fig. S8-S11, ESI $\dagger$ ), where the homopolymer PANT shows a larger root-mean-square (RMS) value of $1.30 \mathrm{~nm}$ (Fig. 3e) due to its higher crystallinity according to the DSC curves (Fig. S2a-d, ESI $\dagger$ ), and the other three D-A polymers exhibit an amorphous morphology with lower RMS values in the range of 0.53 to $0.69 \mathrm{~nm}$ (Fig. 3f-h). Although the overall performance is relatively low for these four polymers, which we attribute to the large dihedral angles and low crystallinity, the successful operation of transistors with these polymers indicates the promise of ANT-based polymers in OFETs. Compared with reported polymers and small molecules based on ANT, as shown in Table S5 (ESI $\dagger$ ), our newly reported polymers exhibit comparable performance. However, the overall 
a

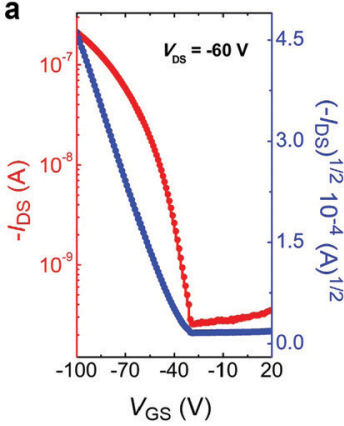

e

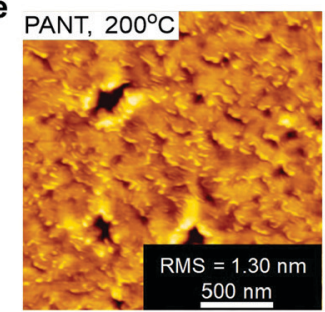

i PANT, $200^{\circ} \mathrm{C}$

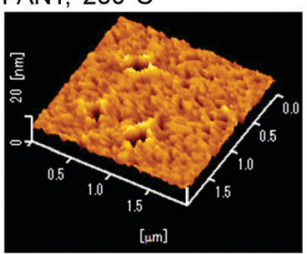

b

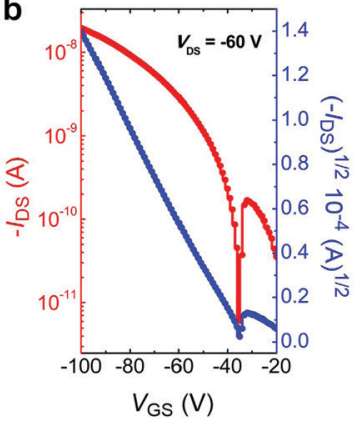

$f$ PANT-TBO, $200^{\circ} \mathrm{C}$

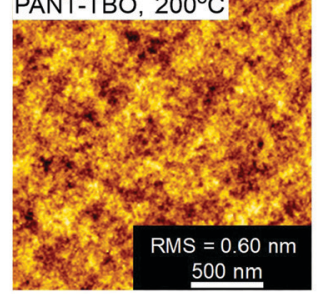

j PANT-TBO, $200^{\circ} \mathrm{C}$

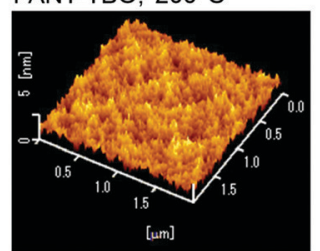

C

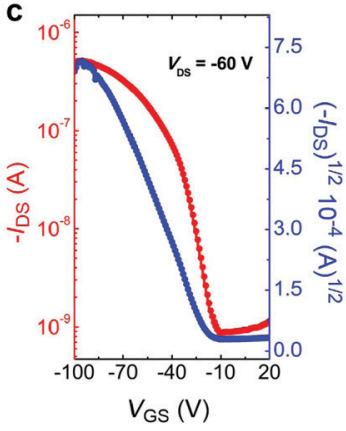

g

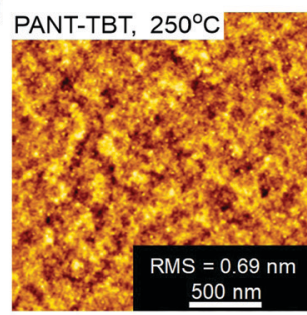

k

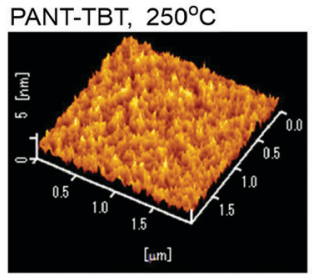

d

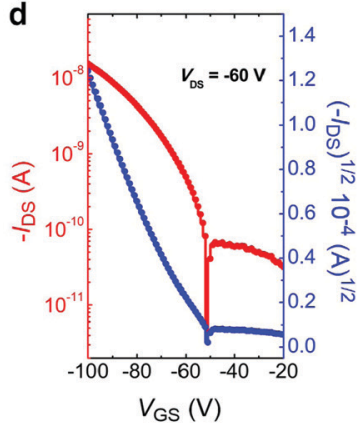

h

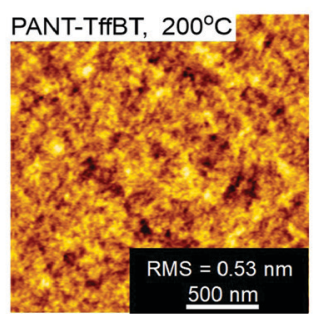

I PANT-TffBT, $200^{\circ} \mathrm{C}$

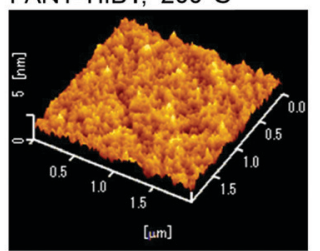

Fig. 3 The transfer characteristics of OFETs based on (a) PANT, (b) PANT-TBO, (c) PANT-TBT, and (d) PANT-TffBT films annealed at optimized temperatures $(L=100 \mu \mathrm{m}$ and $W=1 \mathrm{~mm}$, all the devices were measured under laboratory ambient conditions.) (e-h) Tapping-mode AFM topography images of the four polymers and $(\mathrm{i}-\mathrm{l})$ their corresponding 3D profiles after the optimized thermal annealing treatments.

performance of ANT-based materials is lower than that of anthracene-based ones, ${ }^{41,42}$ and this could be attributed to the lower crystallinity of ANT polymers than their counterparts based on anthracene. We strongly believe that rational molecular design is a key requirement for improving the backbone planarity. The backbone planarity will favour better intermolecular interactions and subsequently higher crystallinity, which is needed for an enhancement in charge carrier transport.

\section{Organic photovoltaic device performance}

To analyse the bulk-heterojunction (BHJ) OPV device performance, ITIC-Th ${ }^{43}$ (Fig. 4a) was used as a small molecule nonfullerene acceptor (SMA) to match with our four new polymers. ITIC-Th was chosen since it offers complementary absorption

Table 2 Summary of the TC/BG OFET data based on the four polymers

\begin{tabular}{llllll}
\hline Materials & $\begin{array}{l}\text { Annealing } \\
\text { temp. }\left({ }^{\circ} \mathrm{C}\right)\end{array}$ & $\begin{array}{l}\mu_{\max }^{\mathrm{h}} / \mathrm{cm}^{2} \mathrm{~V}^{-1} \\
\mathrm{~s}^{-1}\end{array}$ & $\begin{array}{l}\mu_{\text {avg }}^{\mathrm{h}} / \mathrm{cm}^{2} \\
\mathrm{~V}^{-1} \mathrm{~s}^{-1}\end{array}$ & \multicolumn{2}{l}{$V_{\text {th }}(\mathrm{V}) I_{\mathrm{ON}} / I_{\mathrm{OFF}}$} \\
\hline PANT & 200 & $2.2 \times 10^{-3}$ & $2.0 \times 10^{-3}$ & -32 & $10^{3}-10^{4}$ \\
PANT-TBO & 200 & $2.9 \times 10^{-4}$ & $2.3 \times 10^{-4}$ & -33 & $10^{3}-10^{4}$ \\
PANT-TBT & 250 & $4.5 \times 10^{-3}$ & $3.6 \times 10^{-3}$ & -16 & $10^{3}-10^{4}$ \\
PANT-TffBT & 200 & $5.0 \times 10^{-4}$ & $4.5 \times 10^{-4}$ & -50 & $10^{3}-10^{4}$
\end{tabular}

${ }^{a}$ The average values were calculated from 3 devices. $V_{\text {th }}$ stands for threshold voltage. to all the polymers and decent device performance in binary blend $\mathrm{BHJ}$ devices. OPVs were fabricated using the conventional device configuration of ITO/PEDOT:PSS/active layer/PFN$\mathrm{Br} / \mathrm{Ag}$. To further enhance the device performance, an additional acceptor $\mathrm{YG}^{44}$ (Fig. 4b) was introduced into the optimal binary system to form a ternary blend. The weight ratio of the active layer was kept constant at 1:1.5 (polymer donor:total acceptor) to obtain a fair comparison. The energy levels of the used materials are shown in Fig. 4c. The current-voltage $(J-V)$ characteristics and external quantum efficiency (EQE) of all the devices are shown in Fig. $4 \mathrm{~d}$ and e.

As shown in Table 3, the OPVs based on PANT-TBT exhibit higher performance with the power conversion efficiency (PCE) of $4.57 \%$ for the binary and $5.21 \%$ for the ternary blend devices. The reported solar cell device performance is one of the highest values in comparison to all other reported ANT-based materials, and this is summarized in detail in Scheme S1 in the ESI. $\dagger$ The better performance of PANT-TBT compared to the other polymers can be realized mainly due to its higher $J_{\mathrm{SC}}$ and better FF. The higher $J_{\mathrm{SC}}$ value of the PANT-TBT based device matches well with the higher intensity in the EQE curve. Generally, a high EQE value indicates that the photon absorbed by the blend film is efficiently converted to free charge carriers and they are transported to their respective electrodes. Compared to PANTTBT:ITIC-Th, which exhibits a maximum $J_{\mathrm{SC}}$ of $10.45 \mathrm{~mA} \mathrm{~cm}{ }^{-2}$, 
a

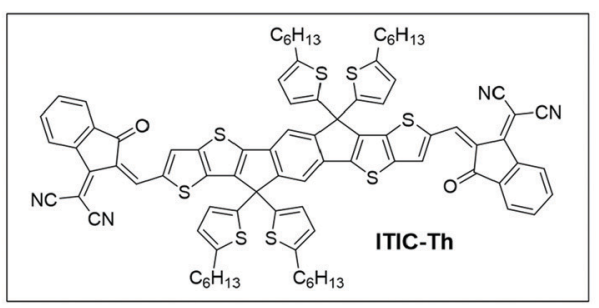

c

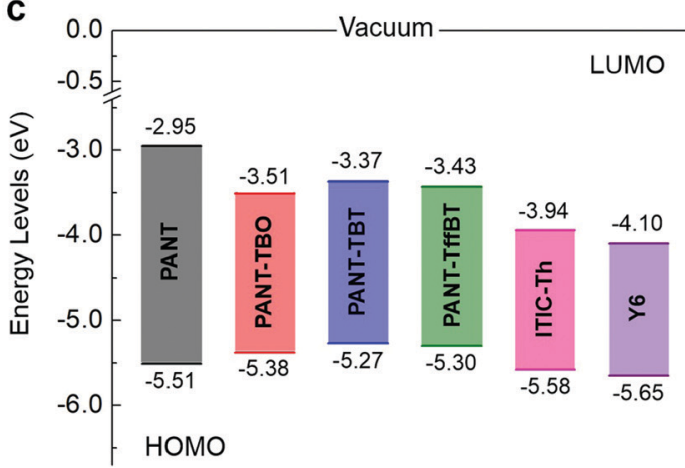

e

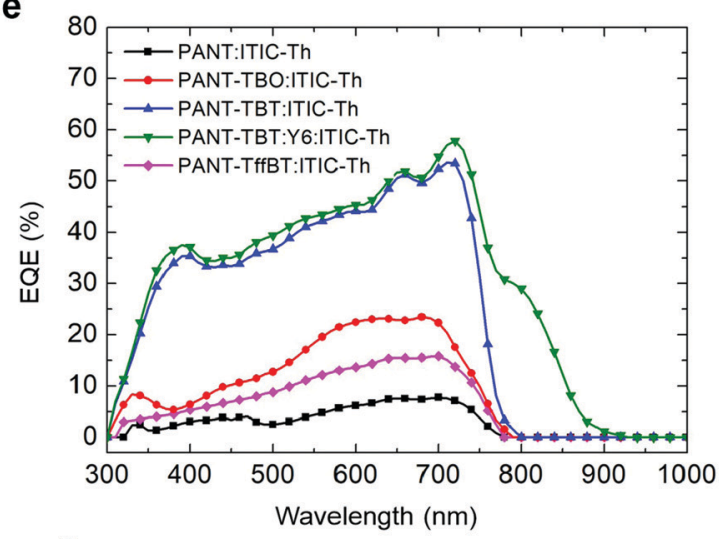

b

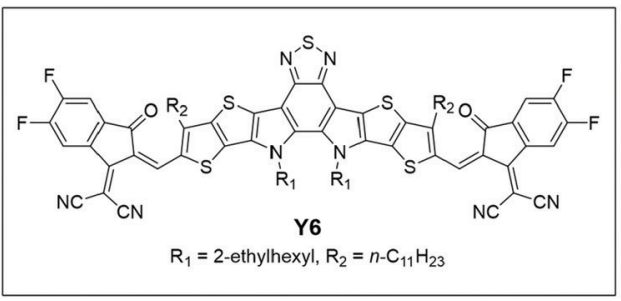

d

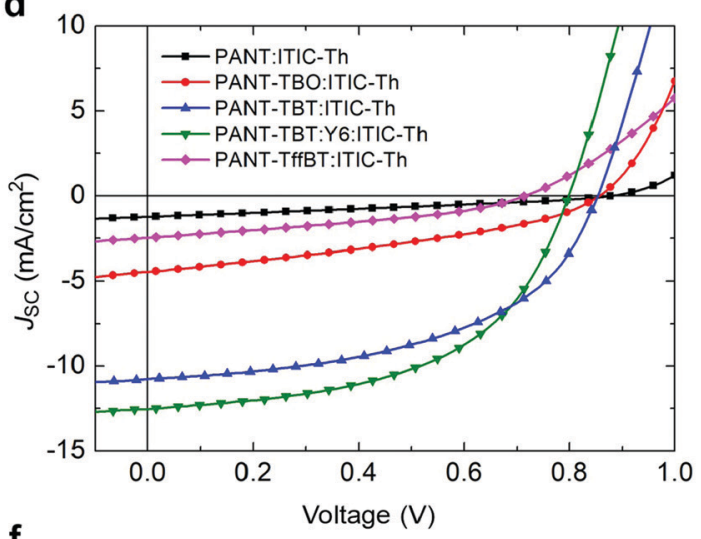

f

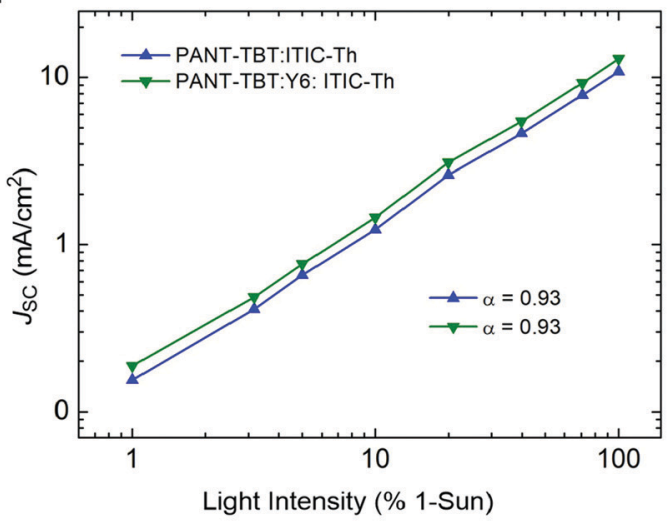

h

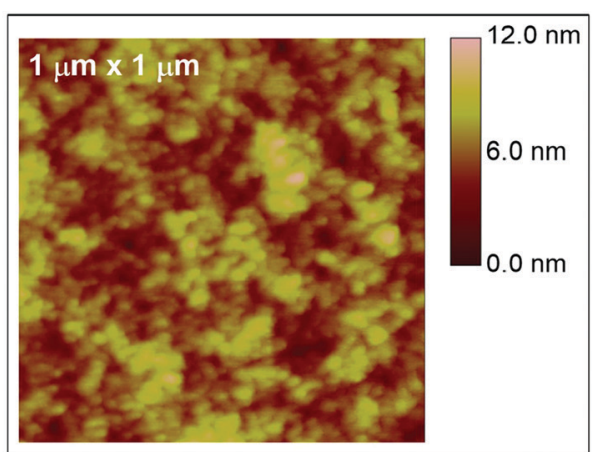

Fig. 4 Chemical structures of (a) ITIC-Th and (b) Y6; (c) energy level diagram of different materials used in this study; (d) J-V characteristics of ANT polymer-based solar cells under AM 1.5G illumination (100 mW cm ${ }^{-2}$ ), and (e) their EQE spectra; (f) recombination analysis of $J_{\mathrm{SC}}$ vs. light intensity; and AFM images of PANT-TBT based (g) ternary and (h) binary blend films.

the ternary blend PANT-TBT:Y6:ITIC-Th shows an increase in $J_{\mathrm{SC}}$ value with a maximum value of $12.75 \mathrm{~mA} \mathrm{~cm}^{-2}$. The increase in $J_{\mathrm{SC}}$ value of the ternary blend can be ascribed to the red-shifted absorption of the Y6 acceptor, which can be seen from the EQE curve. Since Y6 has a lower-lying LUMO compared to ITIC-Th, the $0.05 \mathrm{~V}$ difference in $V_{\mathrm{OC}}$ between binary and ternary devices based on PANT-TBT correlates well with the energetic difference between the HOMO of the donor polymer and LUMO of the acceptor molecules.

In OPVs, the overall device performance can be reduced when the recombination is the most dominant mechanism because of the loss of photogenerated free charge carriers. ${ }^{45}$ In order to 
Table 3 The performance of OPVs based on four different polymers blended with an acceptor

\begin{tabular}{|c|c|c|c|c|c|c|}
\hline Polymer & Acceptor & Ratio & $\begin{array}{l}V_{\mathrm{OC}} \\
(\mathrm{V})\end{array}$ & $\begin{array}{l}J_{\mathrm{SC}} \\
\left(\mathrm{mA} \mathrm{cm}{ }^{-2}\right)\end{array}$ & $\mathrm{FF}$ & $\begin{array}{l}\text { PCE } \\
(\%)\end{array}$ \\
\hline PANT & ITIC-Th & $1: 1.5$ & 0.86 & 1.11 & 0.29 & 0.28 \\
\hline PANT-TBO & ITIC-Th & $1: 1.5$ & 0.84 & 4.03 & 0.35 & 1.18 \\
\hline $\begin{array}{l}\text { PANT-TBT } \\
\text { (binary) }\end{array}$ & ITIC-Th & $1: 1.5$ & 0.85 & 10.45 & 0.51 & 4.57 \\
\hline $\begin{array}{l}\text { PANT-TBT } \\
\text { (ternary) }\end{array}$ & ITIC-Th \& Y6 & $1: 1.5$ & 0.80 & 12.75 & 0.51 & 5.21 \\
\hline PANT-TffBT & ITIC-Th & $1: 1.5$ & 0.71 & 2.20 & 0.36 & 0.56 \\
\hline
\end{tabular}

understand the extent of bimolecular recombination in the PANT-TBT based devices, the $J_{\mathrm{SC}}$ was plotted $v s$. light intensity on a logarithmic scale, as shown in Fig. 4f. In general, if $\alpha$ is close to unity for a power-law dependence $\left(J_{\mathrm{SC}} \propto I^{\alpha}\right)$, this indicates weak bimolecular recombination in the devices. ${ }^{46,47}$ The PANT-TBT binary, as well as ternary, devices exhibit a similar value of $\alpha$ of 0.93 , which indicates a reasonable amount of bimolecular recombination in the devices. Atomic force microscopy (AFM) images were recorded to analyse the top surface of the PANT-TBT based blend morphologies (Fig. $4 \mathrm{~g}$ and $\mathrm{h}$ ). The root-mean-square (RMS) surface roughness values of the binary and ternary films were found to be 1.426 and $1.364 \mathrm{~nm}$, respectively. Addition of Y6 clearly makes the surface slightly smoother than the binary blend. Also, as shown in Fig. $4 \mathrm{~g}$ and $\mathrm{h}$, both binary and ternary blend films display desired phase separation and domain size with a very smooth surface. The BHJ morphology is highly dependent on many factors including, but not limited to, the best donor/acceptor ratio, miscibility between two components, processing solvents (and their drying kinetics), additives, and post-treatment (such as thermal or solvent vapour annealing). ${ }^{48-51}$ The wide range of PCE values from $0.28 \%$ to $5.21 \%$ achieved for the OPVs based on the four ANT polymers clearly demonstrates how important it is to tune the energy levels, optical absorption, and polymer blend morphology via selecting appropriate comonomers. We strongly believe that the performance can be improved further by investigating new materials using various comonomers and other relevant attributes.

\section{Chemical sensor performance}

The newly developed ANT-based polymers have different acceptor units, which are expected to have varying interactions with organic gases, leading to unique detection/sensing capabilities of each polymer. In this study, OFET devices were used to investigate the sensing behaviour of the polymers toward four representative organic compounds, namely, octane, toluene, isopropanol and acetic acid, which have varying chemical and physical properties (Fig. 5a). Based on the OFET transfer curves and for simplicity, we focus on the parameter of on-current $\left(I_{\mathrm{ON}}\right)$ to analyse the responses and the detection ability. For example, the transfer curves of PANT recorded upon exposure to different concentrations of acetic acid are shown in Fig. 5b; a shift in the curve, which is translated to a shift of threshold voltage $\left(V_{\text {th }}\right)$, is clearly seen with increasing concentrations. Fig. $5 \mathrm{c}$ and d show the responses of $I_{\mathrm{ON}}$ of the four polymers upon exposure to various concentrations of acetic acid and octane. The detection ability of acetic acid is higher than that of octane for all types of sensors. This can be explained by the very weak interaction with octane for which the detection mode is only limited to van der Waals interactions, whereas acetic acid has a more polar structure and can interact with the polymers by hydrogen bonds and dipolar interactions, leading to higher detection abilities. The sensitivities and detection limits are summarized in Table S6 (ESI $\dagger$ ). It is very important to note the varying response trends and magnitudes obtained with the four sensors. For octane (Fig. 5d), two sensors based on PANT and PANT-TffBT show almost no response in the range of 160-1280 ppm, while PANT-TBO and PANT-TBT show negative and positive trends, respectively. The PANT-TBT sensor has the highest sensitivity compared to the other polymers. For acetic acid (Fig. 5c), PANT, PANT-TBO, and PANT-TffBT show negative trends and varying sensitivities ranging from $-0.017 \mathrm{ppm}^{-1}$ (PANT-TffBT) to $-0.031 \mathrm{ppm}^{-1}$ (both PANT and PANT-TBO). PANT-TBT exhibits a very interesting behaviour that involves both positive and negative response trends. At low concentrations, there is an increase in the current with increasing concentration, whereas at high concentrations, the current decreases with increasing concentration. This behaviour might be explained by two sensing mechanisms: at low concentrations, PANT-TBT (p-type polymer) is doped by the acid, leading to a higher conductivity. However, when the concentration becomes higher, this trend is reversed possibly due to the detrimental effect of swelling, which increases the distances between the ordered polymer domains and the boundary resistance and, as a result, decreases the value of $I_{\mathrm{ON}}$. The different magnitudes and trends of responses endow each one of the polymers with a unique sensing performance.

Inspired by the nature of olfactory systems, we have used an array of cross-reactive features, obtained from the different OFET characteristics, with pattern recognition methods for optimizing the selectivity toward the different chemical compounds. ${ }^{52}$ This approach was previously used with OFET gas sensors and enabled successful discrimination even between very similar organic compounds such as isomers. ${ }^{53,54}$ For this purpose, the responses of the four OFET sensors were combined using Discrimination Functional Analysis (DFA). New parameters were defined using this method, CV1 and $\mathrm{CV} 2$, which were obtained from the linear combination of the responses of the four semiconductors. The combination of cross-reactive parameters was optimized to improve the discrimination. Fig. 5e shows that the plot of CV2 vs. CV1 gives a clear separation between the chemical compounds in the range of $160-1280 \mathrm{ppm}$ with an accuracy value of $\sim 85 \%$. This large-range discrimination is limited by the low concentrations of propanol and toluene, which are observed as an overlap between the red and blue regions. This work strengthens the important role of the chemical compositions of semiconducting polymers in generating different chemical sensitivities and fingerprints. The remarkable versatility and uniqueness of each sensor would be very beneficial for developing advanced sensing methods that mimic the performance of the human nose. 
a

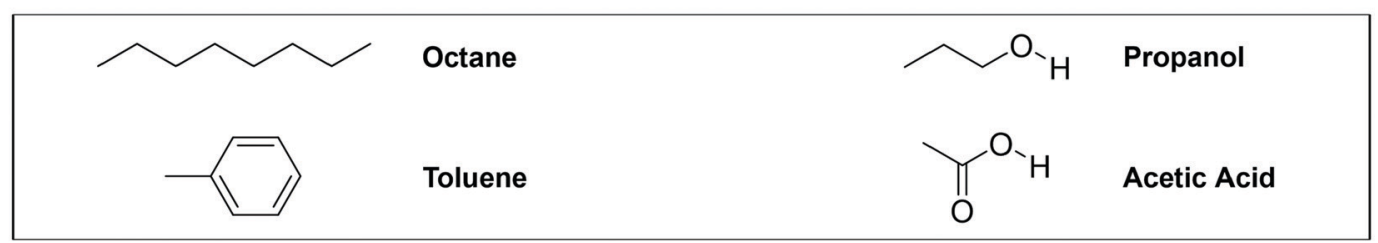

\section{b}
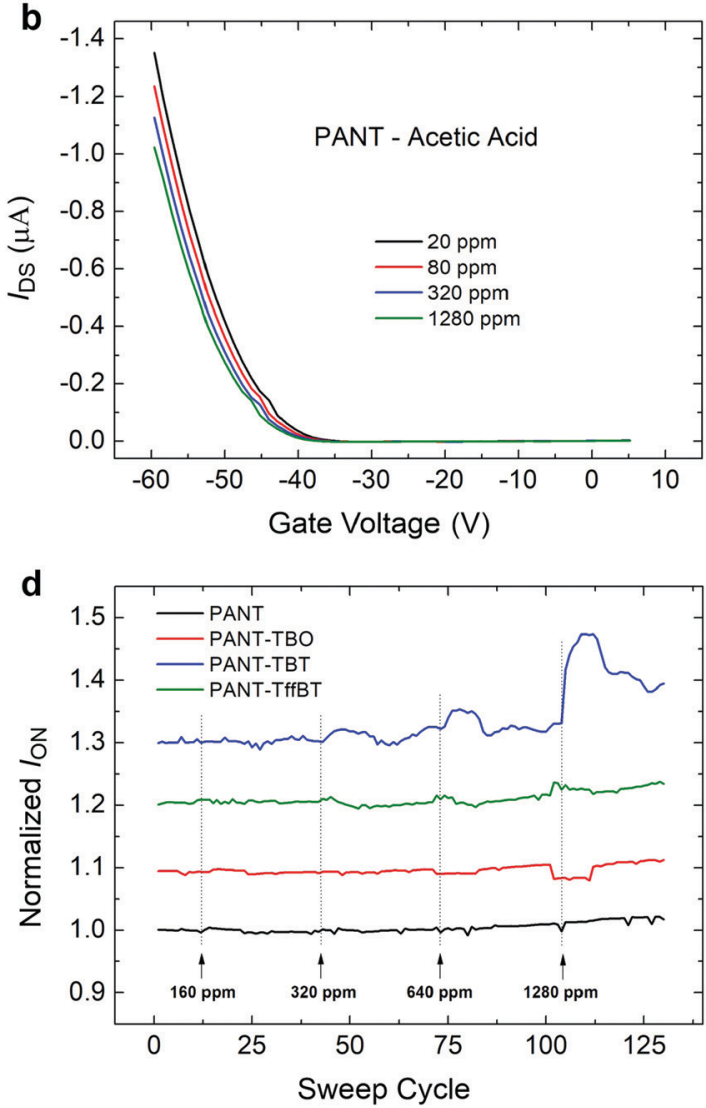
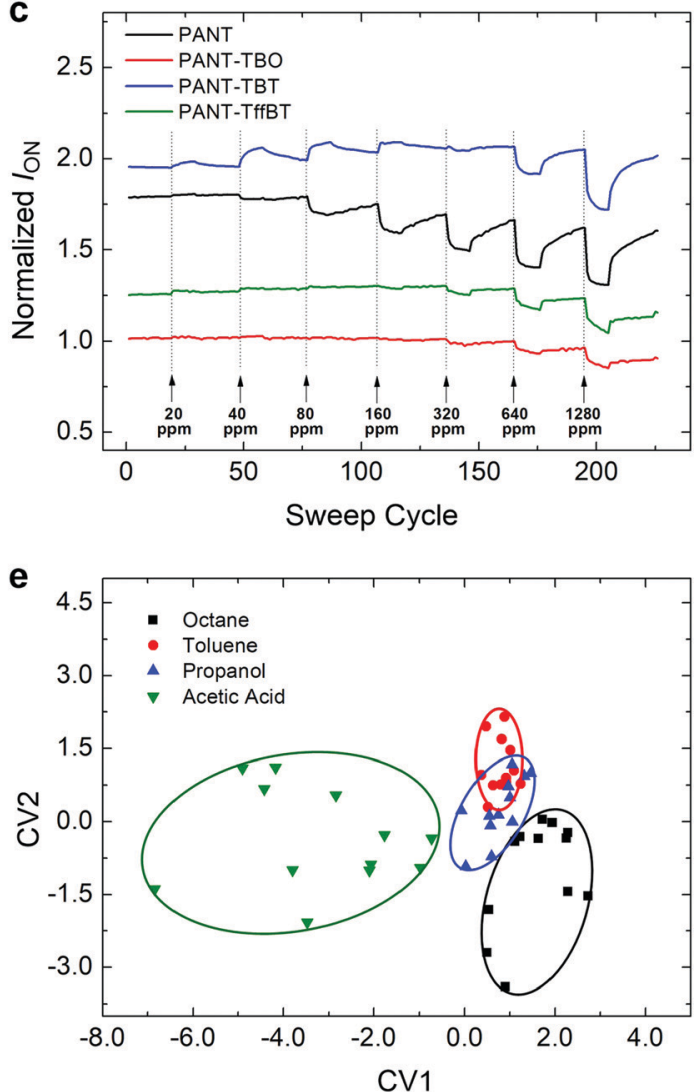

Fig. 5 Investigation of the sensing performance. (a) The chemical structures of four different chemical compounds used in the gas sensing experiments; (b) transfer curves of PANT-OFET recorded upon exposure to different concentrations of acetic acid; normalized $I_{\text {ON }}$ of the four polymers upon exposure to varying concentrations of (c) acetic acid in the range of 20-1280 ppm and (d) octane in the range of 160-1280 ppm; (e) discrimination between all studied chemical compounds over 160-1280 ppm. CV1 and CV2 were obtained by a linear combination between the responses of all four semiconductors using discrimination functional analysis (DFA).

\section{Conclusions}

To summarise, the versatility of four newly synthesized ANTbased polymers, PANT, PANT-TBO, PANT-TBT, and PANTTffBT, is studied in detail by applying them in three different types of electronic devices, namely OFETs, OPVs, and chemical sensors. It is encouraging that these four ANT polymers all display decent performance in OFETs, OPVs and chemical sensors. For example, PANT-TBT exhibits a hole mobility of $4.5 \times 10^{-3} \mathrm{~cm}^{2} \mathrm{~V}^{-1} \mathrm{~s}^{-1}$ in OFETs and a PCE of $5.21 \%$ in ternary blend OPVs when mixing it with non-fullerene acceptors ITICTh and Y6 as the active layer. In sensors, the four polymers show varying response trends for octane, toluene, isopropanol and acetic acid, indicating the important role of the structural composition in generating different chemical sensitivities and fingerprints. Overall, in this work, we have clearly disclosed the multi-purpose applications of ANT-based polymers in various types of electronic devices. This is a new scenario in the organic electronics community, and we have done pioneering work in this aspect by adapting ANT-based polymeric semiconductors. It is expected that ANT could become a significant building block for the construction of high-performance OSCs for advancing various photovoltaic and electronic devices.

\section{Experimental section}

The synthetic routes to the four polymers are shown in Scheme 1. Unless otherwise stated, the starting compounds were purchased commercially and used directly without further purification. The solvents used were anhydrous.

\section{Synthesis of C24-ANT}

Under argon protection, ANT (1.00 g, $2.15 \mathrm{mmol}), \mathrm{Na}_{2} \mathrm{~S}_{2} \mathrm{O}_{4}$ (940 mg, $5.40 \mathrm{mmol})$, Aliquat $336(1.15 \mathrm{~g}, 2.58 \mathrm{mmol})$, aqueous 
$\mathrm{NaOH}(0.1 \mathrm{M}, 100 \mathrm{~mL}, 10 \mathrm{mmol})$ and 2-decyltetradecyl bromide $(7.18 \mathrm{~g}, 17.2 \mathrm{mmol})$ were added into a $250 \mathrm{~mL}$ round flask. The mixture was heated to $60{ }^{\circ} \mathrm{C}$ and kept stirring overnight. When the temperature was cooled to room temperature, the water was decanted, and methanol was added. The crude product was filtered and washed with methanol. The pure product C24-ANT $(1.50 \mathrm{~g}, 1.32 \mathrm{mmol}$, yield $=61 \%)$ as an orange solid can be obtained by performing column chromatography with hexane as the eluent. ${ }^{1} \mathrm{H}$ NMR $\left(\mathrm{CDCl}_{3}, 600 \mathrm{MHz}\right), \delta$ (ppm), 8.61-8.54 $(\mathrm{m}, 6 \mathrm{H}), 8.12(\mathrm{~d}, J=7.8 \mathrm{~Hz}, 2 \mathrm{H}), 4.15-4.12(\mathrm{~m}, 4 \mathrm{H}), 2.12-2.09$ $(\mathrm{m}, 2 \mathrm{H}), 1.88-1.84(\mathrm{~m}, 4 \mathrm{H}), 1.73-1.68(\mathrm{~m}, 4 \mathrm{H}), 1.60-1.32$ (m, 72H), 0.94-0.90 (m, 12H).

\section{Synthesis of BE-C24-ANT}

A dry flask under argon was charged with C24-ANT (1.50 g, $1.32 \mathrm{mmol}$ ), bis(pinacolato)diboron (1.02 g, $4.00 \mathrm{mmol})$, anhydrous potassium acetate $(518 \mathrm{mg}, 5.28 \mathrm{mmol})$ and $\left[1,1^{\prime}-\right.$ bis(diphenylphosphino)ferrocene]dichloropalladium(II) (Pd(dppf) $\mathrm{Cl}_{2}$, $51 \mathrm{mg}, 0.070 \mathrm{mmol})$, and the flask was flushed three times with a vacuum/argon cycle. Anhydrous 1,4-dioxane $(20 \mathrm{~mL})$ was added, and the reaction was heated to $110{ }^{\circ} \mathrm{C}$ for $12 \mathrm{~h}$. After the mixture was cooled, $\mathrm{MeOH}(100 \mathrm{~mL})$ was added, and the crude product was obtained after filtration. It was further purified through silica gel column chromatography with hexane : dichloromethane $=10: 1$ as the eluent, giving $\sim 850 \mathrm{mg}$ (yield $=52 \%$ ) of BE-C24-ANT as a yellow to red sticky liquid. ${ }^{1} \mathrm{H} \mathrm{NMR}\left(\mathrm{CDCl}_{3}, 600 \mathrm{MHz}\right), \delta(\mathrm{ppm}), 9.20(\mathrm{~s}, 4 \mathrm{H}), 8.81(\mathrm{~s}, 2 \mathrm{H})$, $8.21(\mathrm{~s}, 2 \mathrm{H}), 4.31(\mathrm{~d}, J=5.4 \mathrm{~Hz}, 4 \mathrm{H}), 2.25(\mathrm{~s}, 2 \mathrm{H}), 1.96-1.91(\mathrm{~m}, 4 \mathrm{H})$, 1.78-1.72 (m, 4H), 1.56 (s, 24H), 1.49-1.30 (m, 72H), 0.91 (m, 12H).

\section{General procedure for polymer synthesis}

In a $50 \mathrm{~mL}$ Schlenk flask, BE-C24-ANT (308 mg, $0.250 \mathrm{mmol}$ ) and dibromo compounds $(0.250 \mathrm{mmol})$ were dissolved in toluene $(10 \mathrm{~mL}) .2 \mathrm{M} \mathrm{K}_{2} \mathrm{CO}_{3}(5 \mathrm{~mL})$ and 2 drops of Aliquat 336 were added to the above reaction mixture. The solution was purged with argon for $30 \mathrm{~min}$, and then tetrakis(triphenylphosphine) palladium (11 $\mathrm{mg}, 0.010 \mathrm{mmol}$ ) was added. The reaction was stirred at $80{ }^{\circ} \mathrm{C}$ for 3 days. Then, a solution of 4-methoxyphenylboronic acid was added, followed by the addition of 2-bromothiophene, and the mixture was stirred overnight. The resulting mixture was poured into a mixture of methanol $(100 \mathrm{~mL})$ and water $(100 \mathrm{~mL})$ and stirred overnight. The precipitated dark solid was filtered off and re-dissolved in chloroform and added dropwise to methanol $(250 \mathrm{~mL})$. The resulting solid was filtered off and subjected to Soxhlet extraction with methanol (24 h), acetone $(24 \mathrm{~h})$ and hexane $(24 \mathrm{~h})$, respectively. The residue was finally extracted with chloroform or chlorobenzene and precipitated again using methanol, filtered, washed with methanol, and dried under vacuum. PANT: $M_{\mathrm{n}}=20.9 \mathrm{kDa} ; M_{\mathrm{w}}=50.6 \mathrm{kDa} ; \mathrm{PDI}=2.42$. Anal. calcd for $\mathrm{C}_{70} \mathrm{H}_{108} \mathrm{O}_{2}$ : C 85.65, $\mathrm{H} 11.09$, O 3.26; found: $\mathrm{C} 86.27, \mathrm{H} 9.582$. PANT-TBO: $M_{\mathrm{n}}=26.0 \mathrm{kDa} ; M_{\mathrm{w}}=72.3 \mathrm{kDa}$ PDI $=2.78$. Anal. calcd for $\mathrm{C}_{84} \mathrm{H}_{114} \mathrm{~N}_{2} \mathrm{O}_{3} \mathrm{~S}_{2}$ : C 79.82, $\mathrm{H}$ 9.09, $\mathrm{N} 2.22$, O 3.80, S 5.07; found: C 79.56, H 7.855, N 2.15, S 5.228. PANT-TBT: $M_{\mathrm{n}}=24.7 \mathrm{kDa}$; $M_{\mathrm{w}}=61.9 \mathrm{kDa}$; PDI $=2.51$. Anal. calcd for $\mathrm{C}_{84} \mathrm{H}_{114} \mathrm{~N}_{2} \mathrm{O}_{2} \mathrm{~S}_{3}: \mathrm{C} 78.82$, H 8.98, N 2.19, O 2.50, S 7.51; found: C 79.54, H 7.961, N 1.97, S 7.606.
PANT-TffBT: $M_{\mathrm{n}}=8.4 \mathrm{kDa} ; M_{\mathrm{w}}=27.3 \mathrm{kDa}$ PDI $=3.25$. Anal. calcd for $\mathrm{C}_{84} \mathrm{H}_{112} \mathrm{~F}_{2} \mathrm{~N}_{2} \mathrm{O}_{2} \mathrm{~S}_{3}$ : C 76.67, $\mathrm{H}$ 8.58, F 2.89, N 2.13, O 2.43, S 7.31; found: C 75.00, H 7.149, N 2.27, S 8.628.

\section{Authors contributions}

Qian Liu designed, synthesized and characterized the polymer materials, and managed the completion of the whole manuscript. Yang Wang and Tsuyoshi Michinobu are responsible for the results of organic field-effect transistor performance and helped in the discussion. Lingeswaran Arunagiri and He Yan are responsible for the results of organic photovoltaic device performance and helped in the discussion. Muhammad Khatib and Hossam Haick are responsible for the chemical sensing results and helped in the discussion. Sergei Manzhos helped in the Density Functional Theory (DFT) calculation and manuscript revision. Krishna Feron helped with the photoelectron spectroscopy in air (PESA) measurement. Steven E. Bottle helped with the manuscript revision. Prashant Sonar conceived and directed the project. All authors have reviewed or commented on the final version of the manuscript.

\section{Conflicts of interest}

There are no conflicts to declare.

\section{Acknowledgements}

Qian Liu is thankful to QUT for offering the QUTPRA scholarship to conduct his research. P. S. is thankful to QUT for the financial support from the Australian Research Council (ARC) for the Future Fellowship (FT130101337) and QUT core funding (QUT/322120-0301/07). Some of the data reported in this paper were obtained at the Central Analytical Research Facility (CARF) operated by the Institute for Future Environments (QUT). Access to CARF was supported by generous funding from the Science and Engineering Faculty (QUT). Sergei Manzhos is supported by the Natural Sciences and Engineering Research Council of Canada. S. M. thanks Compute Canada.

\section{Notes and references}

$1 \mathrm{H}$. Klauk, Organic electronics: materials, manufacturing, and applications, John Wiley \& Sons, 2006.

2 X. Guo and A. Facchetti, Nat. Mater., 2020, 19, 922-928.

3 K. Yang, X. Zhang, A. Harbuzaru, L. Wang, Y. Wang, C. Koh, H. Guo, Y. Shi, J. Chen, H. Sun, K. Feng, M. C. Ruiz Delgado, H. Y. Woo, R. P. Ortiz and X. Guo, J. Am. Chem. Soc., 2020, 142, 4329-4340.

4 Q. Liu, S. Kumagai, S. Manzhos, Y. Chen, I. Angunawela, M. M. Nahid, K. Feron, S. E. Bottle, J. Bell, H. Ade, J. Takeya and P. Sonar, Adv. Funct. Mater., 2020, 30, 2000489.

5 Q. Liu, Y. Wang, A. Kohara, H. Matsumoto, S. Manzhos, K. Feron, S. E. Bottle, J. Bell, T. Michinobu and P. Sonar, Adv. Funct. Mater., 2020, 30, 1907452. 
6 S. Yuvaraja, A. Nawaz, Q. Liu, D. Dubal, S. G. Surya, K. N. Salama and P. Sonar, Chem. Soc. Rev., 2020, 49, 3423-3460.

7 B. Zheng, L. Huo and Y. Li, NPG Asia Mater., 2020, 12, 3.

8 M. Urbani, M. Gratzel, M. K. Nazeeruddin and T. Torres, Chem. Rev., 2014, 114, 12330-12396.

9 W. Li, Q. Liu, Y. Zhang, C. Li, Z. He, W. C. H. Choy, P. J. Low, P. Sonar and A. K. K. Kyaw, Adv. Mater., 2020, 32, 2001591.

10 NREL, https://www.nrel.gov/pv/cell-efficiency.html, accessed: September 2020.

11 M. Kim, S. U. Ryu, S. A. Park, K. Choi, T. Kim, D. Chung and T. Park, Adv. Funct. Mater., 2019, 30, 1904545.

12 C. Yan, S. Barlow, Z. Wang, H. Yan, A. K. Y. Jen, S. R. Marder and X. Zhan, Nat. Rev. Mater., 2018, 3, 18003.

13 H. D. Pham, X. Li, W. Li, S. Manzhos, A. K. K. Kyaw and P. Sonar, Energy Environ. Sci., 2019, 12, 1177-1209.

14 Q. Liu, H. Sun, C. Blaikie, C. Caporale, S. Manzhos, K. Feron, J. M. MacLeod, M. Massi, S. E. Bottle, J. Bell, Y.-Y. Noh and P. Sonar, New J. Chem., 2018, 42, 12374-12385.

15 F. Hide, M. A. Diaz-Garcia, B. J. Schwartz, M. R. Andersson, Q. Pei and A. J. Heeger, Science, 1996, 273, 1833-1836.

16 Q. Liu, S. E. Bottle and P. Sonar, Adv. Mater., 2020, 32, 1903882.

17 H. Yao, L. Ye, H. Zhang, S. Li, S. Zhang and J. Hou, Chem. Rev., 2016, 116, 7397-7457.

18 E. Wang, W. Mammo and M. R. Andersson, Adv. Mater., 2014, 26, 1801-1826.

19 M. J. Robb, S.-Y. Ku, F. G. Brunetti and C. J. Hawker, J. Polym. Sci., Part A: Polym. Chem., 2013, 51, 1263-1271.

20 Y. Wang, T. Hasegawa, H. Matsumoto, T. Mori and T. Michinobu, Adv. Mater., 2018, 30, 1707164.

21 Y. Li, P. Sonar, L. Murphy and W. Hong, Energy Environ. Sci., 2013, 6, 1684-1710.

22 L. Huo, J. Hou, S. Zhang, H. Y. Chen and Y. Yang, Angew. Chem., Int. Ed., 2010, 49, 1500-1503.

23 J. Y. Back, H. Yu, I. Song, I. Kang, H. Ahn, T. J. Shin, S.-K. Kwon, J. H. Oh and Y.-H. Kim, Chem. Mater., 2015, 27, 1732-1739.

24 L. Meng, Y. Zhang, X. Wan, C. Li, X. Zhang, Y. Wang, X. Ke, Z. Xiao, L. Ding, R. Xia, H.-L. Yip, Y. Cao and Y. Chen, Science, 2018, 361, 1094-1098.

25 J.-F. Morin, J. Mater. Chem. C, 2017, 5, 12298-12307.

26 J.-B. Giguère, Q. Verolet and J.-F. Morin, Chem. - Eur. J., 2013, 19, 372-381.

27 A. Lafleur-Lambert, J.-B. Giguère and J.-F. Morin, Polym. Chem., 2015, 6, 4859-4863.

28 W. Bradley and J. Waller, J. Chem. Soc., 1953, 3783-3786.

29 A. Lafleur-Lambert, J.-B. Giguère and J.-F. Morin, Macromolecules, 2015, 48, 8376-8381.

30 J. B. Giguere, J. Boismenu-Lavoie and J. F. Morin, J. Org. Chem., 2014, 79, 2404-2418.

31 K. L. Platt, C. Degenhardt, S. Grupe, H. Frank and A. Seidel, Chem. Res. Toxicol., 2002, 15, 332-342.

32 S. V. John, V. Cimrova, C. Ulbricht, V. Pokorna, A. Ruzicka, J. B. Giguere, A. Lafleur-Lambert, J. F. Morin, E. Iwuoha and D. A. M. Egbe, Macromolecules, 2017, 50, 8357-8371.
33 J. B. Giguere and J. F. Morin, J. Org. Chem., 2015, 80, 6767-6775. 34 P. Sarkar, S. Sato, S. Kamata, T. Matsuno and H. Isobe, Chem. Lett., 2015, 44, 1581-1583.

35 J. B. Giguere and J. F. Morin, J. Org. Chem., 2013, 78, 12769-12778.

36 S. L. Broman, C. L. Andersen, T. Jousselin-Oba, M. Manso, O. Hammerich, M. Frigoli and M. B. Nielsen, Org. Biomol. Chem., 2017, 15, 807-811.

37 S.-H. Yi, S. Ohashi, K. Ogino, H. Sato and H. Nomori, Synth. Met., 1993, 61, 247-251.

38 D. Alezi, Y. Belmabkhout, M. Suyetin, P. M. Bhatt, Ł. J. Weseliński, V. Solovyeva, K. Adil, I. Spanopoulos, P. N. Trikalitis, A.-H. Emwas and M. Eddaoudi, J. Am. Chem. Soc., 2015, 137, 13308-13318.

39 Y. Li, Acc. Chem. Res., 2012, 45, 723-733.

40 Y. J. Kim, J. S. Lee, J. Hong, Y. Kim, S. B. Lee, S.-K. Kwon, Y.-H. Kim and C. E. Park, J. Polym. Sci., Part A: Polym. Chem., 2016, 54, 2559-2570.

41 K. H. Jung, S. Y. Bae, K. H. Kim, M. J. Cho, K. Lee, Z. H. Kim, D. H. Choi, D. H. Lee, D. S. Chung and C. E. Park, Chem. Commun., 2009, 5290-5292.

42 J. Y. Ma, H.-J. Yun, S.-O. Kim, G. B. Lee, H. Cha, C. E. Park, S.-K. Kwon and Y.-H. Kim, J. Polym. Sci., Part A: Polym. Chem., 2014, 52, 1306-1314.

43 Y. Lin, F. Zhao, Q. He, L. Huo, Y. Wu, T. C. Parker, W. Ma, Y. Sun, C. Wang, D. Zhu, A. J. Heeger, S. R. Marder and X. Zhan, J. Am. Chem. Soc., 2016, 138, 4955-4961.

44 J. Yuan, Y. Zhang, L. Zhou, G. Zhang, H.-L. Yip, T.-K. Lau, X. Lu, C. Zhu, H. Peng, P. A. Johnson, M. Leclerc, Y. Cao, J. Ulanski, Y. Li and Y. Zou, Joule, 2019, 3, 1140-1151.

45 C. Brabec, U. Scherf and V. Dyakonov, Organic photovoltaics: materials, device physics, and manufacturing technologies, John Wiley \& Sons, 2011.

46 Z. Li, J. D. Lin, H. Phan, A. Sharenko, C. M. Proctor, P. Zalar, Z. Chen, A. Facchetti and T. Q. Nguyen, Adv. Funct. Mater., 2014, 24, 6989-6998.

47 L. Koster, V. Mihailetchi, H. Xie and P. Blom, Appl. Phys. Lett., 2005, 87, 203502.

48 X. Guo, M. Zhang, J. Tan, S. Zhang, L. Huo, W. Hu, Y. Li and J. Hou, Adv. Mater., 2012, 24, 6536-6541.

49 A. Mayer, M. F. Toney, S. R. Scully, J. Rivnay, C. J. Brabec, M. Scharber, M. Koppe, M. Heeney, I. McCulloch and M. D. McGehee, Adv. Funct. Mater., 2009, 19, 1173-1179.

50 C. McDowell, M. Abdelsamie, M. F. Toney and G. C. Bazan, Adv. Mater., 2018, 30, 1707114.

51 J. Zhao, Y. Li, G. Yang, K. Jiang, H. Lin, H. Ade, W. Ma and H. Yan, Nat. Energy, 2016, 1, 15027.

52 S. Stewart, M. A. Ivy and E. V. Anslyn, Chem. Soc. Rev., 2014, 43, 70-84.

53 B. Wang, T. P. Huynh, W. Wu, N. Hayek, T. T. Do, J. C. Cancilla, J. S. Torrecilla, M. M. Nahid, J. M. Colwell, O. M. Gazit, S. R. Puniredd, C. R. McNeill, P. Sonar and H. Haick, Adv. Mater., 2016, 28, 4012-4018.

54 M. Khatib, T.-P. Huynh, J. J. Sun, T. T. Do, P. Sonar, F. Hinkel, K. Müllen and H. Haick, Adv. Funct. Mater., 2019, 29, 1808188. 